\title{
Mathematical problem appearing in industrial lumber drying: A review
}

\author{
Edi Cahyono \\ Dept. Mathematics FMIPA Univ. Halu Oleo, Kendari, Indonesia \\ Email address: \\ edi_cahyono@innov-center.org
}

To cite this article:

Edi Cahyono. Mathematical Problem Appearing in Industrial Lumber Drying: A Review. Science Journal of Applied Mathematics and Statistics. Vol. 2, No. 1, 2014, pp. 26-30. doi: 10.11648/j.sjams.20140201.14

\begin{abstract}
This article is a review of our work on the modeling of lumber drying that we have started in 2003 . We consider a lumber drying process in a kiln chamber where from mathematical point of views, this is an initial and boundary value problem. The Moisture Content (MC) is measured at the center of the lumber by applying a nail that thousands times of the pore size of the wood. This leads to apply macro modeling for the diffusion process of the water inside the lumber. MC acts as the state variable $u$ of the thickness $x$ and time $t$. The state variable satisfies a diffusion equation. The Equilibrium Moisture Content (EMC) of the air acts as the boundary condition. We report the progress on mathematical modeling and compared the results with data from industry.
\end{abstract}

Keywords: Boundary Value Problem, Initial Value Problem, Diffusion Equation, Lumber Drying

\section{Introduction}

This article is a review of our previous work reported in [1, $2,3,4,5]$ by elaborating recent understanding of modeling. From industrial point of view, a good drying process is very much of the interest, especially of lumber and timber industries. Good process prevents the lumber from developing surface cracks and several other defects. Drying may reduce lumber weight by a factor two or more meaning lower cost on transportation. Drying increases the lumber strength; nails, screws and glue hold better, paint and finishes adhere well. Dry lumber is a better thermal insulator than the wet one (see [14] for details).

The moisture content (MC) of lumber is an important aspect on lumber drying. MC of lumber is defined as the ratio of the mass of water contained in the lumber to the mass of the lumber without water. MC of some fresh log cut from a tree may be above $100 \%$. Industries dry lumbers to have MC around $6 \%$ to $20 \%$, which is hard to achieve naturally. To have good control on lumber drying, middle and large sizes timber industries dry lumber in (kiln) ovens.

This paper focuses on understanding the drying inside the lumber based on the process in a kiln oven of an industry, a review of our research focus started in 2003. Understanding the process better will be a starting point for an efficient process. Most previous and current researches are experimental tests or purely modeling and simulation; [10,
$11,12,13]$ are among others. In this paper we consider modeling, simulation and comparison with real data obtained in an industry.

\section{Industrial Process and Data}

Drying process decreases the cross-sectional dimension of the lumber up to ten percent. Fig. 1 show an illustrative results of lumber drying process. Lumber which is dried too quickly, leaving the surface much drier than the inside, may develop cracks on the surface. If one surface is significantly drier than the other, the lumber may bend. A good drying process should not develop these mal-forms, except reducing dimension. Therefore a good process should dry the lumber evenly. Understanding this mechanism is extremely important to find an optimal drying time.

The moisture content (MC) of lumber is an important aspect on lumber drying. MC of lumber is defined as the ratio of the mass of water contained in the lumber to the mass of the lumber without water. MC of some fresh $\log$ cut from a tree may be above $100 \%$. Some industries dry lumbers for $\mathrm{MC}$ around $10 \%$ to $15 \%$. To have good control on lumber drying, middle and large sizes timber industries dry lumber in ovens. The moisture content of the lumber before entering the oven varies around $50 \%$ to $70 \%$. The drying process in the oven is done by controlling the Equilibrium Moisture Content (EMC), i.e. the air humidity 
in the oven. To make the process faster, the EMC should be lower, and vice versa. While drying process of the surface of lumber is directly controlled by setting the EMC, drying the inside part very much depends on the surface and also the type of lumber, hence is not easily controlled.

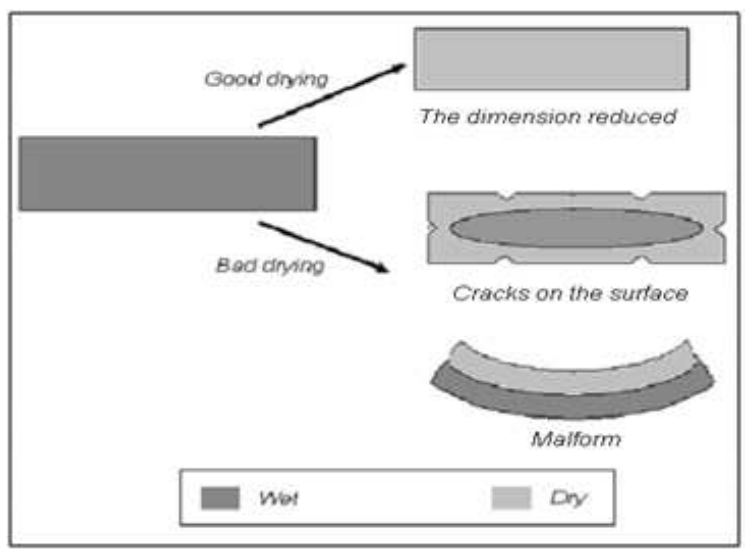

Figure 1. Illustration of good drying and bad drying process of lumber in industry.

Fig. 2 show illustrative plot of a kiln chamber (oven), devices used to measure MC and EMC, and controlling the process of drying by setting the EMC. The kiln chamber is equipped with heating and fans, where EMC can be set up by blowing up the humid air out of the chamber and/or increasing the temperature in it. Some fans are also used to create uniform EMC in the oven. EMC is automatically control by using computer software for drying.

The data recorded from the drying process in the kiln chamber are EMC and MC as time series. We consider lumber durian wood (Durio zibethinus) of the dimension of $5 \mathrm{~cm} \times 40 \mathrm{~cm} \times 250 \mathrm{~cm}$. The process is recorded in the interval of 6 days.

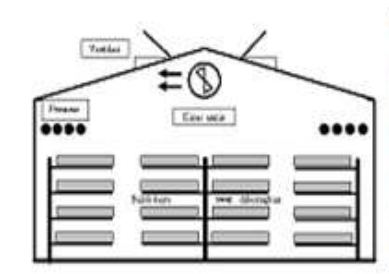

(a)

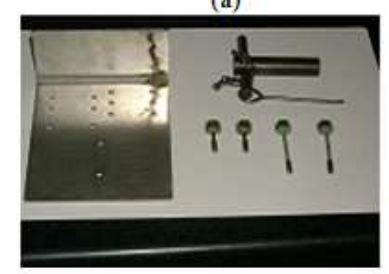

(c)

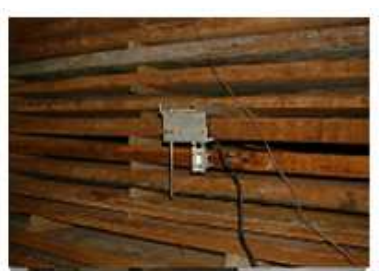

(b)

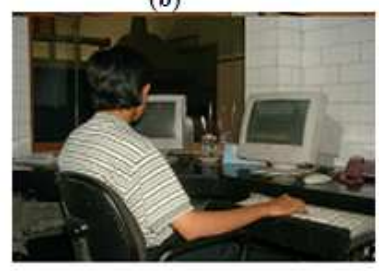

(d)
Figure 2. Drying process, measuring MC and setting EMC in industry.

\section{Mathematical Model}

We consider spatial variable $x \in \mathfrak{R}^{n}$, and temporal variable $t \in \mathfrak{R}$. A state variable representing the mass density (of water) at the point $x$ inside the wood and time $t$ is denoted by $u=u(x, t)$. The flux of mass $v$ at point $x$ to the surrounding points is assumed linearly depends on the gradient of $u$ at $x$; the larger the gradient, the larger the flux. Hence, we have

$$
v=K \cdot \nabla u
$$

where $K$ is a factor that may be constant or a function $x$ or $u$.

Let $\Omega \subset \mathfrak{R}^{n}$ be bounded, and the boundary is denoted by $\partial \Omega$. Assuming the mass conserved, the total mass leaving $\Omega$ is given by

$$
\int_{\partial \Omega} v \bullet n d A
$$

where $\boldsymbol{v} \bullet \boldsymbol{n}$ denotes the component $\boldsymbol{v}$ in the direction of normal vector $\boldsymbol{n}$. Applying Gauss divergence theorem, we have

$$
\int_{\partial \Omega} v \bullet \boldsymbol{n} d A=-\int_{\Omega} \nabla \bullet(K \cdot \nabla u) d V
$$

where $\nabla^{2} u$ is a Laplace operator applied to $u$.

On the other hand, the total mass in $\Omega$ is the integral of the mass density over $\Omega$

$$
m=\int_{\Omega} u d V
$$

The rate of change of the mass

$$
\frac{d m}{d t}=\int_{\Omega} \frac{\partial u}{\partial t} d V
$$

Positive sign of $d m / d t$ refers to the increase of mass in $\Omega$, on the contrary the negative sign refers to the decrease of mass. Assuming the mass conserved, the total mass leaving $\Omega$ is equal to the decrease of mass inside $\Omega$. Hence, we have

$$
-\int_{\Omega} \frac{\partial u}{\partial t} d V=-\int_{\Omega} \nabla \cdot(K \cdot \nabla u) d V
$$

which is equivalent to

$$
\int_{\Omega}\left(\frac{\partial u}{\partial t}-\nabla \cdot(K \cdot \nabla u)\right) d V=0
$$

Since $\Omega$ is any subset of $\Re^{n}$ and restricting on a continuous integrand, we have

$$
\frac{\partial u}{\partial t}=\nabla \cdot(K \cdot \nabla u) .
$$

Such derivation can be found in many standard textbooks including, the one well-known for engineering [8].

Notes:

The relation of the water density and the moisture content is given by 


$$
\bar{u}(x, t)=u_{\mathrm{Wood}} u(x, t)
$$

where $\bar{u}(x, t)$ is water content at point $x$ and time $t$, and $u_{\text {wood }}$ is the wood density. The wood density is assumed to be constant, it does not depend on $x$. On substituting (9) into (8), we have

$$
\frac{\partial \bar{u}}{\partial t}=\nabla \cdot(\bar{K} \cdot \nabla \bar{u})
$$

Dropping the bar, $u(x, t)$ stands for the moisture content at $(x, t)$. Hence, either moisture content or mass (of water) density is governed by (8).

\section{Method}

We will compare the solution of our model with real data of $\mathrm{MC}$ of the lumber during the drying process. Note that the measurement of MC at center of the lumber, however, includes its surrounding area, but small, about hundreds or thousands of the pore size of wood. Hence, the MC does not refer only at a single point. Rather, it refers to an average quantity in its neighborhood. This technique is known as Representative Elementary Volume (REV), (see [7]).

The numerical solution of the model (8) is computed numerically using a finite difference method. This method has been widely discussed in standard books such as [9]. For the numerical computation we use $\Delta x=0.1$, and the time step $\Delta t=0.01$. The boundary condition is taken from the linear interpolation of the industrial data of EMC. The information of initial condition is limited in three points, two on the boundary and one in the center of the lumber. We may interpret the initial condition in two ways. The first, it is assumed to be constant equals to the initial data of MC in the center. Second, it is assumed to be quadratic function taken from the initial data of MC at the center and the EMC at the two boundary points. This illustrated in Fig. 3.

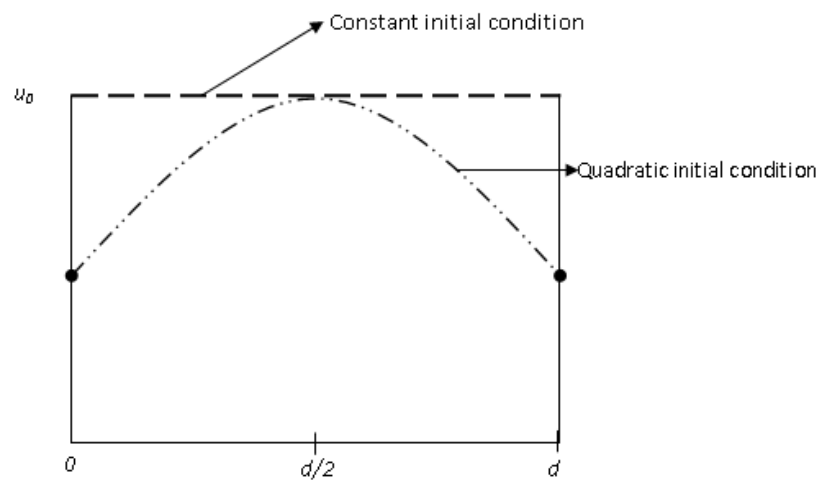

Figure 3. Quadratic initial condition and constant initial condition.

\section{Results and Discussion}

Fig. 4 shows the real (industrial data) of EMC, MC and numerical result of the state variable at the center for the case that the initial condition is constant and equals to the initial MC. Note that EMC acts as boundary condition of the simulation. Observe that the model gives a mismatch of the real data and numerical solution in the beginning of drying process. This mismatch is removed by applying quadratic interpolation of MC in the center and EMC at the two boundary points as the initial condition as presented in Fig. 5.

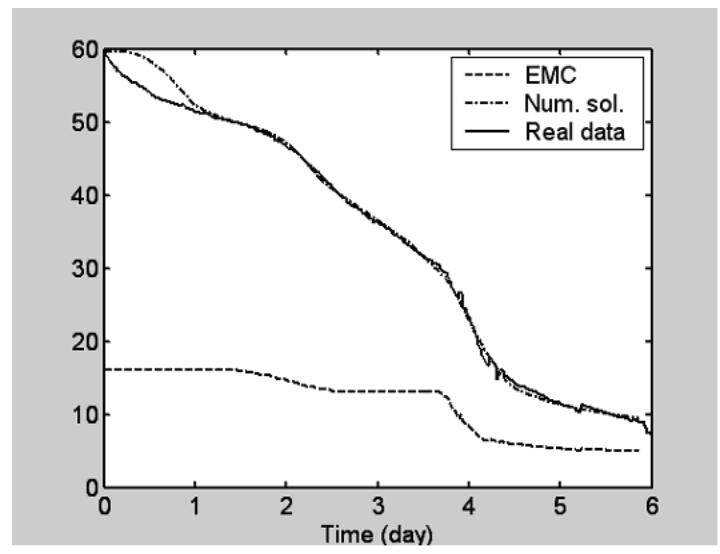

Figure 4. EMC, MC and numerical result of the state variable at the center for the case of constant initial condition.

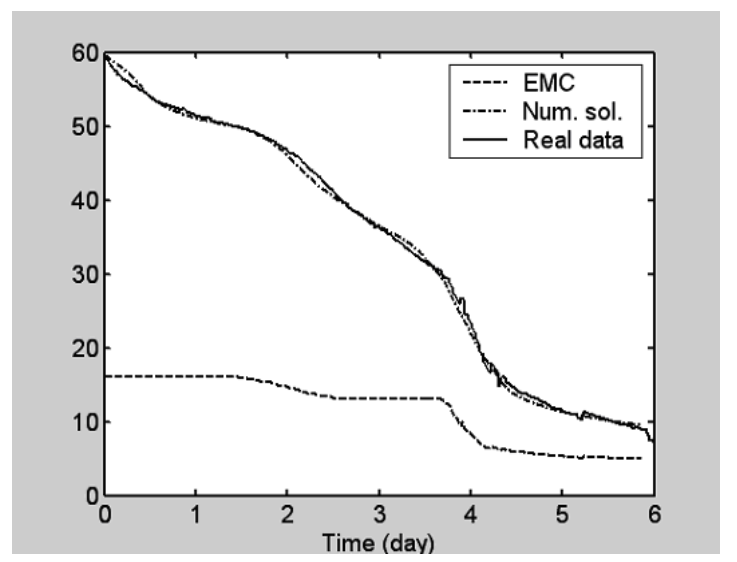

Figure 5. EMC, MC and numerical result of the state variable at the center for the case of quadratic initial condition.

We have presented mathematical model development of drying process of wood. We have also compared with real data from an industry. Our discussion, however, is a direct problem of initial and boundary value problem meaning given the diffusion equation accompanied with the initial and boundary conditions. The problem faced by the operators and technicians in an industry is how to determine EMC (boundary condition) such that they get the prescribed MC (state variable). This means that given

$$
\frac{\partial u}{\partial t}=\partial_{x}\left(K(u) \cdot \partial_{x} u\right), 0<\mathrm{x}<\mathrm{d} \text { and } \mathrm{t}>0 .
$$

The initial condition is given by

$$
\begin{aligned}
& \mathrm{u}=\mathrm{f}(\mathrm{x}), \text { in } 0<\mathrm{x}<\mathrm{d} \\
& u(d / 2, t)=g(t) .
\end{aligned}
$$


Find the boundary condition $\mathrm{u}(0, \mathrm{t})=\mathrm{u}(\mathrm{d}, \mathrm{t})=\mathrm{h}(\mathrm{t})$.

On the other hand, the function $K$ for specific wood is still unknown. This also yields another inverse problem below. Given

$$
\frac{\partial u}{\partial t}=\partial_{x}\left(K \cdot \partial_{x} u\right), 0<\mathrm{x}<\mathrm{d} \text { and } \mathrm{t}>0 .
$$

The initial and boundary conditions are given by

$$
\begin{aligned}
& u=f(x), \text { in } 0<x<d \\
& u(0, t)=u(d, t)=h(t) .
\end{aligned}
$$

An additional signal is also known, say

$$
u(d / 2, t)=g(t)
$$

Find the diffusion rate $\mathrm{K}$. For the case $\mathrm{K}$ constant and a function of $x$, it is already discussed in $[6,15,16]$. For the case of wood drying in general, $\mathrm{K}=\mathrm{K}(\mathrm{x}, \mathrm{u})$ a function that depends on the spatial and state variables $\mathrm{x}$ and $\mathrm{u}$.

\section{Conclusion}

We have discussed a development of mathematical model of wood drying for a lumber. The model based on an assumption where the width and the length are significantly larger than the thickness. Hence, the drying process is governed by a 1-D diffusion equation. The state variable represents the moisture content (MC) of the lumber at spatial variable and temporal variable $x$ and $t$, respectively. Industrial data indicate that the diffusion rate depends on the type of wood, and also MC itself. Therefore, the model is governed by a nonlinear diffusion equation accompanied by initial and boundary conditions.

The mathematical expression of the diffusion rate as a function of the state variable is still unknown. The development of the model partly is the approximation of the diffusion rate, starting from a step function to a smooth one. On the other hand, initial condition from industry merely give data at the center and outside of the lumber. We considered two cases of initial conditions; assuming it is constant and equals to the MC at the center, and quadratic function connecting the $\mathrm{MC}$ at boundary points and the center.

We solved the diffusion equation numerically using a finite difference method. The boundary condition is a linear interpolation of the industrial data of Equilibrium Moisture Content (EMC). The solution at the center of the wood has been compared to the industrial data of MC. We show that the solution is a good approximation for the industrial data of MC. Moreover, the numerical solution is smoother than the industrial data which is more preferable in the industries. For the case of constant initial condition, there exist significant mismatch at the beginning of the process. This mismatch is not observed when we applied the quadratic initial condition.

\section{Acknowledgements}

Part of the research was supported by Ditjen Dikti, Kemendikbud Republik Indonesia. The author thanks the management of PT Harison \& Gil Java and Mr. Muh. Solikan for the fruitfull discussion.

\section{References}

[1] E. Cahyono \& La Gubu, "Wood drying process: modeling for linear diffusivity with respect to the water content", Proceeding SEMINAR MIPA IV ITB, Bandung Indonesia, 2004, pp. 112-114.

[2] E. Cahyono, D. C. Tjang \& La Gubu, "Modeling of wood drying", Proceedings of International Conference on Mathematics And Its Applications, Yogyakarta Indonesia, 2003, pp. 227-232.

[3] E. Cahyono, "Modeling of Wood Drying: A Step Function Approach to the Diffusivity," Proceedings of the 2nd International Conference on Research and Education in Mathematics, Kuala Lumpur, Malaysia, 2005, pp. 358-364.

[4] E. Cahyono, Y Soeharyadi \& Mukhsar, "A smooth diffusion rate model of wood drying: a simulation toward more efficient process in industry," Jurnal Teknik Industri, vol. 10, no. 1, 2008, pp. 1-10.

[5] La Gubu \& E. Cahyono, "A quasi-linear diffusivity approach for diffusion process of lumber drying," Proceedings of the International Conference on Applied Mathematics, Bandung, Indonesia, 2005, pp. 1002-1006.

[6] N. S. Hoang and A. G. Ramm, "An inverse problem for a heat equation with piece wise constant thermal conductivity," Journal of Mathematical Physics, vol. 50, 2009, no. 063512.

[7] U. Hornung, Homogenization and Porous Media, Springer-Verlag, Berlin, 1997.

[8] E. Kreyszig, Advanced Engineering Mathematics, 7th ed., John Wiley \& Son, Singapore, 1999.

[9] K. W. Morton \& D. F. Mayers, Numerical Solution of Partial Differential Equations, Cambridge University Press, Cambridge, 1996.

[10] S. Omarsson, Numerical analysis of moisture related distortion in sawn timber, $\mathrm{PhD}$ thesis, Dept. of Structural Mechanics, Chalmers University of Technology, Goteborg, Sweden, 1999.

[11] S. Ormarsson, D. Cown and O. Dahlblom, "Finite element simulations of moisture related distortion in laminated timber products of Norway spruce and radiata pine," in $8^{\text {th }}$ International IUFRO Wood Drying Conference, 2003, pp. 27-33.

[12] S. Omarsson, O. Dahlblom, and H. Peterson, "A numerical study of shape stability of sawn timber subjected to moisture variation. Part 2: Simulation of drying board," Wood Science and Technology, vol. 33, 1999, pp. 407-423.

[13] S. Omarsson, O. Dahlblom, and H. Peterson, "A numerical study of shape stability of sawn timber subjected to moisture variation. Part 3: Influence of annual ring orientation," Wood Science and Technology, vol. 34, 2000, pp. 207-219. 
[14] J. Passard and P. Perre, "Creep test under water-saturated conditions: do the anisotropy ratios of wood change with the temperature and time dependency?", $7^{\text {th }}$ International IUFRO Conference on Wood Drying, 2001.

[15] A. G. Ramm. An inverse problem for heat equation. Journal of Mathematical Analysis and Applications, 2001, vol. 264, pp. 691-697.

[16] A. G. Ramm, "An inverse problem for the heat equation II," Applied Analysis, 2002, vol. 81, no. 4, pp. 929-937. 